\title{
A Study of Polymer Additive in Crushed Rock Soil Aggregate Improvement for Highway Construction in Suphan Buri
}

\author{
Thanatip Jarearnsiri ${ }^{1}$, Sideth Prum ${ }^{2}$, Thattep Wattanaphrayapa ${ }^{1}$, Gerard Duggan ${ }^{3}$, Nalinee Jumnongpol ${ }^{4}$ \\ ${ }^{1}$ Suphan Buri, Rural Road Office \\ Bureau of Rural Roads 18 (Suphan Buri), Thailand \\ thanatip_na@hotmail.com; thathep19@gmail.com \\ ${ }^{2}$ Suvannaphum Investment Co., Ltd \\ Sangkat BoengKak II, Phnom Penh, Cambodia \\ sidethprum@gmail.com \\ ${ }^{3}$ Civil Engineering Technical Advisor, KBR \\ Perth, Australia \\ Duggan.Gerard@jkc-lng.com \\ ${ }^{4}$ Metropolitan Waterworks Authority \\ 400 Prachachuen Road, Laksi, Bangkok, Thailand \\ nalinee.j@mwa.co.th
}

\section{Extended Abstract}

Presently, material problem is an important factor for highway construction, especially the material that does not meet required specifications for Department of Highway (DH) Standard and Department of Rural Road (DRR) Standard, Thailand. Bureau of Rural Road 18 (Suphan Buri) also face problems with soil aggregates. Those materials meet required specifications for subbase layers are rarely available in close proximity to construction areas[1]. They can be found in provinces such as Sara Buri and Kanchana Buri central and western part of Thailand, respectively. These provinces are far from the construction site which will impact the cost and the control of material standard. Material choice is an important consideration for highway construction agencies, including the Bureau of Rural Road 18 (Suphan Buri).

This paper aims to study the physical properties and compressive strength of crushed rock soil aggregate (CRS) improved with polymer additives, which is to be used as a highway construction material [2]. The samples were prepared based on the optimum moisture content (OMC) and the maximum dry density from the modified proctor test by ASTM standard. Each sample was prepared using cylindrical mold with inner diameter of $101.5 \mathrm{~mm}$ and height of $116.5 \mathrm{~mm}$. CRS samples were mixed with a cement content of $2 \%, 4 \%$ and $6 \%$ by weight and Chem Road binder added at $0 \%, 2 \%$, $4 \%$ and $6 \%$ rate by concentration of solution. The ASTM standard D2166-850, D1883, and D5084 were used in the physical property studies of the samples.

The results show that strength development of crushed rock soil aggregate using cement at the ration of $2 \%, 4 \%$ and $6 \%$ are significantly increased due to the presence of Chem Road (Chem) concentration binder. The maximum 28 days strength of CRS-Cement with Chem is $7.25 \mathrm{MPa}$ for a cement ratio of $6 \%$ and a Chem concentration of $6 \%$. The Chem Road concentration is a predominant factor in the increase in compressive strength of CRS development compared to others. The permeable properties and Modulus of Elasticity are also significantly improved by the Chem Road additive. Additionally, it is shown that Chem Road improved the flexibility of the pavement. Finally, results show that all sample mixtures with a cement content of $4 \%$ and $6 \%$ and with any Chem Road concentration above $0 \%$ can give higher strength than that specified by DH-s204/2533 \& DRR 244-2556 (Thailand) for a soil cement layer in highway construction.

\section{References}

[1] D. T. Bergado, Report on Evaluations and Tests of Laterite Soil Stabilized with CHEMROAD and cement. Asian Insitute of Technology: AIT Press, 2010.

[2] S. Horpibulsuk, D. T. Bergado, and G.A. Lorenzo. (2015, May 25). Compressibility of cement admixed clays at high water content. [Online]. Available: https://www.icevirtuallibrary.com/doi/10.1680/geot.2004.54.2.151. 